\title{
Peningkatan Daya Saing Produk Kue Tradisional Berbahan Baku Sagu Di Desa Amahusu Kecamatan Nusaniwe Kota Ambon
}

\author{
Micrets A Silaya ${ }^{1}$, R. Suryanti Ismail2, Beatrix A. Talakua ${ }^{3}$ \\ 1,2,3Universitas Kristen Indonesia Maluku \\ 1makawerumicke85@gmail.com,2yantiismail@gmail.com, 3beatrixadonia07@gmail.com
}

\begin{abstract}
Abstrak
Kegiatan pengabdian masyarakat merupakan salah satu kompenen dalam Tridhrama Perguruan Tinggi. Oleh karena setiap dosen memiliki kewajiban untuk melakukan pengabdian kepada masyarakat. Kegiatan yang dilakukan adalah PKM Peningkatan Daya Saing Produk Kue Tradisional Berbahan Sagu di Desa Amahusu Kecamatan Nusaniwe, Ambon. Kegiatan ini bertujuan untuk meningkatkan pemahaman, melatih dan memberikan pendampingan kepada para mitra penerima manfaat yaitu Kelompok Usaha bunga Cengkeh. Pelaksanaan kegiatan dibagi dalam tiga tahap yaitu : 1) Persiapan (Identifikasi dan sosialisasi), 2) Pelaksanaan (Pelatihan dan Pendampingan), 3) Pelaksanaan Monitoring dan Evaluasi keberhasilan dengan menggunakan metode "participatory rural appraisal" (PRA). Metode ini mengarahkan semua unsur yang terlibat dalam kegiatan ini terutama mitra sasaran, secara bersama-sama menganalisis masalah, merumuskan perencanaan, kebijakan serta saling belajar dan berbagi pengalaman antara TIM PKM dengan Mitra Sasaran dalam bentuk pelatihan dan pendampingan yang dikemas dalam bentuk sosialisasi, diskusi dan demontrasi. Hasil dari pelaksanaan kegiatan ini adalah Mitra sasaran 1)Meningkatnya Pengetahuan mitra sasaran dalam mengembangkan usaha kue tradisional berbahan baku sagu; 2) Mitra sasaran mampu menerapkan model pengemasan produk secara baik; 3) Mitra sasaran mampu menerapkan pencatatan keuangan secara baik.melalui pengemasan produk yang lebih baik, mitra sasaran dapat meningkatkan daya saing serta nilai jual produk dipasaran. Demikian halnya juga dengan kemampuan mitra sasaran dalam pencatatan keuangan berpengaruh pada membaiknya pola pengelolaan keuangan usaha secara benar dan teratur. Melalui pencapaian ini maka dapat disimpulkan bahwa kegiatan PKM telah mendorong mitra sasaran dalam meningkatkan daya saing produk kue tradisional berbahan sagu. Disarankan agar mitra sasaran tetap konsisten dalam menerapkan pengetahuan yang diperoleh dari kegiatan PKM ini.
\end{abstract}

Kata Kunci: Pembukuan; Pengemasan; Sagu; Amahusu

\section{Abstract}

Pengabdian Kepada Masyarakat is the components in Tridhrama College. Because every lecturer has an obligation to perform community service. The activity carried out is PKM Increased Competitiveness of Traditional Cake Products Sagu in Amahusu Village Nusaniwe District, Ambon. This activity aims to improve understanding, training and providing 
assistance to recipient partners benefits, micro businness Bunga Cengkeh. The implementation of activities is divided into three stages, that is: 1) Preparation (Identification and socialization), 2) Implementation (Training and Assistance), 3) Implementation of Monitoring and Evaluation success using the "participatory rural appraisal" (PRA) method. This method directs all the elements involved in this activity especially target partners, jointly analyze the problem, formulate planning, policies as well as mutual learning and sharing experiences between team PKM with target partners in the form of training and mentoring packaged in the form of socialization, discussion and demonstration. The results of implementation This activity is the target partner 1) Increased Knowledge of the target partner in developing a traditional cake business made from sagu; 2) Target partners able to apply the product packaging model; 3) Target partners able to implement good financial records through product packaging better, target partners can increase competitiveness and product sale value on the market. The target has ability in financial records have an effect on improving financial management patterns effort properly and regulary. Through this achievement it can be concluded that PKM activities have encouraged target partners in increasing their power competitiveness of traditional sagu-based cake products. It is recommended that target partners remain consistent in applying the knowledge gained from this PKM activity.

Keywords: accountancy, packaging, sagu, amahusu

\section{Pendahuluan}

Daya saing industri mutlak harus dilakukan agar produk dalam negeri bisa bertahan dari gempuran produk impor (Hidayat, 2010). Fakta mengungkapkan sisi lain pengusaha terutama di daerah-daerah memiliki keterbatasan sumberdaya guna meningkatkan usaha dan pengembangan produk yang berdaya saing (Miranda, 2013). Keterbatasan pengetahuan dan kemampuan manajemen serta informasi pasar relatif membentuk kelemahan operasional dan output unit-unit industri yang sesuai dengan kebutuhan pasar. Publikasi BPS propinsi Maluku tahun 2017 menjelaskan industri makanan sebagai satu jenis industri di Maluku yang mengalami pertumbuhan negatif, publikasi ini secara umum mengungkapkan kelemahan industri makanan di daerah Maluku (Imk, 2018). Sebagai contoh, makanan tradisional khas Maluku dengan menggunakan sagu sebagai bahan dasarnya. Sesuai perkembangan keragaman pangan, Sagu tidak lagi menjadi makanan pokok sebagian masyarakat Maluku, khususnya yang hidup didaerah perkotaan. Sagu telah menjelma menjadi komoditi lain seperti jajanan tradisional. Umumnya masyarakat Maluku mengkonsumsi makanan ini untuk menjamu tamu, sebagai cemilan ataupun sebagai oleh-oleh atau buah tangan. Walaupun dengan berjalannya waktu, banyak pilihan jajanan modern tersedia di pasar. Namun hingga saat ini, makanan tradisional khas Maluku masih tetap menjadi pilihan bagi sebahagian besar masyarakat maluku maupun wisatawan yang berkunjung ke Maluku. Kota Ambon sebagai ibukota Provinsi Maluku serta menjadi pusat pemerintahan, memiliki penduduk sebanyak 395.423 jiwa (Badan Pusat Statistik Kota Ambon, 2016). Kota ambon juga merupakan daerah tujuan wisata yang sarat 
dengan berbagai penyelenggaraan event baik lokal, nasional maupun internasional. Kondisi tersebut turut mendorong berkembangnya berbagai sektor usaha, seperti jasa perhotelan, transportasi, dan perdagangan khususnya usaha kuliner khas Maluku. Salah satu Industri Rumah Tangga yang memproduksi makanan tradisional khas maluku dengan menggunakan sagu sebagai bahan dasarnya adalah Usaha Sagu kering Bungan Cengkeh (Mitra). Usaha sagu kering milik ibu Sofia ini dikelola bersama 5 orang karyawannya secara tradisional. Industri rumah tangga yang terletak di Desa Amahusu Ambon ini memproduksi sagu kering yang dijadikan makanan pokok yang disantap dengan lauk pauk ataupun bisa di konsumsi dengan minuman hangat. Pengelolaan usaha mitra, masih dilakukan secara tradisional dan cenderung tidak terarah. Modal usaha adalah modal sendiri yang digunakan untuk membiayai operasional usaha dan tidak dipisahkan dari keuangan rumah tangga. Sedangkan proses produksi maupun pengemasan, masih bersifat tradisional serta sangat sederhana.

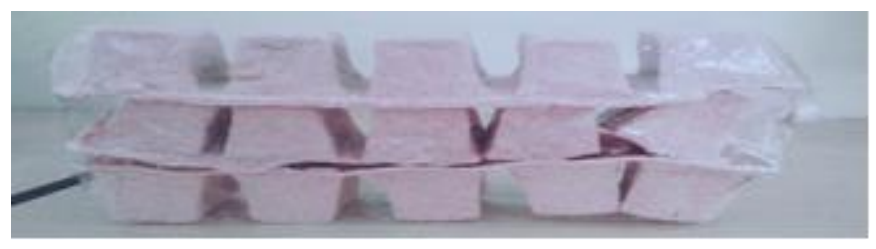

Gambar 1. Kemasan Plastik Bening Tanpa Label

Memperhatikan kemasan produk seperti yang ditunjukkan pada gambar 1 diatas, menunjukkan bahwa produk ini memiliki nilai jual yang rendah apalagi jika dijadikan sebagai oleh-oleh. Kenyataan ini menjadi hambatan besar dalam pengembangan usaha serta peningkatan daya saing produk di pasar. (Erijanto \& Fibrianto, 2018).

Meningkatkan daya saing produk berarti meningkatkan keunggulan kualitas produk dengan berbagai inovasi (Suharman et al., 2018). Pengembangan daya saing produk yaitu dari segi bentuk, rasa, standar kesehatan dan kemasan produk yang digunakan. Tentu tetap memperhatikan nilai-nilai kearifan lokal meski dengan inovasi yang sangat kreatif sebagai nilai sosial yang kompleks (Husain, 2011). Para pengusaha atau pelaku usaha di bidang industri kue tradisional berbahan baku sagu di Amahusu Kecamatan Nusaniwe harus memiliki kompetensi khas dalam hal manajemen kualitis produk. Peningkatan daya saing produk kue tradisional berbahan baku sagu pada prinsipnya merupakan proses menyeluruh. Kualitas merupakan elemen utama bagi peningkatan daya saing suatu produk (Subagyo Pangestu, 2000). Produk kue tradisional berbahan baku sagu dapat lebih mudah memenangkan tingkat persaingan yang kian ketat di pasaran bila kualitasnya selalu terjaga. Kualitas tidak hanya terbatas pada kualitas Produk kue tradisional berbahan baku sagu yang ditawarkan, namun juga meliputi Kualitas layanan yang menyertai penjualan suatu produk.

Menurut (Dismawan, 2014) diantara masalah dasar yang dihadapi UKM adalah kelemahan dalam struktur permodalan, kelemahan dibidang organisasi dan sumberdaya manusia. Berdasarkan hal tersebut dan mempertimbangkan kendala- 
kendala serta keterbatasan yang dihadapi oleh mitra sasaran maka kegiatan ini dilakukan. Tujuannya adalah untuk meningkatkan pemahaman, melatih dan memberikan pendampingan kepada para mitra sasaran sebagai penerima manfaat. Dengan demikian maka kelompok usaha Bunga cengkeh mampu meningkatkan daya saing produknya, yaitu produk kue tradisional berbahan sagu.

\section{Metode}

Beberapa masalah mitra sasaran yang teridentifikasi adalah masalah Manajemen usaha dan pengelolaan keuangan dan Pemasaran. Permasalahan ini merupakan target utama masalah yang harus segera diselesaikan. Berdasarkan analisis situasi dan permasalahan yang dihadapi maka program PKM ini dilaksanakan. Program ini adalah program yang bersifat aktual dalam rangka peningkatan pengetahuan, pemahaman dan ketrampilan Kelompok Mitra bunga cengkeh tentang cara mengelola serta mengembangkan usaha dengan baik. Untuk mencapai tujuan tersebut maka metode yang dipandang sesuai untuk melaksanakan kegiatan ini adalah "participatory rural appraisal" (PRA). Metode ini memungkinkan semua unsur dalam kegiatan ini, terumata Miitra, dalam hal ini adalah pemilik usaha dan karyawannya untuk secara bersama-sama menganalisis masalah dalam rangka merumuskan perencanaan dan kebijakan secara nyata. Metode ini mengarahkan mitra untuk saling berbagi pengalaman, meningkatkan dan menganalisis pengetahuan mereka tentang kondisi dan keberadaanya serta membuat rencana dan tindakan nyata. Dengan demikian, semua unsur dalam kegiatan ini diarahkan untuk saling belajar dan berbagai pengalaman, terlibat dalam kerja sama dan perolehan informasi, melibatkan fasilitator, menggunakan konsep triangulasi, serta optimalisasi hasil, orientasi praktis, dan keberlanjutan program (Hudayana et al., 2019). Program kegiatan ini dalam pelaksanaannya mengacu pada pola sinergi antara tenaga dosen dengan kompetensi yang dibutuhkan dengan praktisi. Selain itu, program ini juga diarahkan pada terciptanya iklim kerjasama yang kolaboratif, mutualis dan demokratis antara perguruan tinggi dengan masyarakat.

Guna mengoptimalkan keberhasilan penyeleasaian masalahan yang dihadapi oleh mitra maka pelaksanaan program ini akan dibagi dalam tiga tahap, yaitu :

1. Tahap Persiapan (Identifikasi dan Sosialisasi).

Pada tahap ini dilakukan koordinasi dan analisis situasi untuk mengidentifikasi permasalahan spesifik mitra dan menyusun konten materi yang yang selanjutnya dirumuskan dalam rancangan kegiatan. Dengan demikian, rancangan model dan jadwal pelaksanaan program dapat disusun serta terintegrasi dengan kesiapan intruktur dan Mitra.

2. Tahap Pelaksanaan (Pelatihan dan Pendampingan)

Pelaksanaan Program kemitraan masyarakat ini berlangsung selama 8 (delapan) bulan yang dimulai sejak tahap persiapan sampai dengan evaluasi program. Tahap pelaksanaan ini terdiri dari Pelatihan dan pendampingan. Bentuk 
pelatihan dan pendampingan dilakukan dalam bentuk sosialisasi, diskusi, dan demontrasi.

3. Tahap Monitoring dan Evaluasi

Untuk mengukur tingkat keberhasilan program, maka dilakukan monitoring dan evaluasi sebanyak 3 (tiga) kali, yaitu evaluasi proses, evaluasi akhir, dan evaluasi tindak lanjut. Kegiatan evaluasi ini melibatkan instruktur dari Fakultas Ekonomi UKIM Ambon. Keberhasilan Kelompok Mitra yang terlibat dalam program ini diukur berdasarkan tingkat perubahan positif yang dicapai berdasarkan indikator-indikator yang telah ditentukan dalam model penyelesaian masalah. Melalui tahap ini diharapkan proses transfer Iptek yang terjadi akan berjalan secara berkesinambungan dan dapat mengembangkan usaha kelompok mitra serta meningkatkan perekonomian anggotanya.

\section{Hasil dan Pembahasan}

Pelaksanaan Program PKM dilakukan di Desa Amahusu Kecamatan Nusaniwe Kota Ambon dilakukan dengan sebagai berikut :

1. Sosialisasi Kewirausahaan, yaitu memberi pengetahuan dan pemahaman kepada mitra sasaran tentang pentingnya membangun mental wirausaha. Hal ini akan menimbulkan semangat berwira usaha bagi peserta kegiatan untuk selalu mempertahankan kelangsungan usahanya ditengan ketatnya persaingan bisnis. Selain itu mitra usaha juga memahami bahwa usaha yang dibangun adalah suatu lembaga bisnis yang perlu dikembangkan dan bukan hanya sekedar untuk mempertahankan hidup. Hal lain yang dibahas dalam sosialisasi ini adalah model-model promosi dalam pemasaran produk. Pada bagian ini, peserta PKM diberi pengetahuan tentang cara melakukan promosi produk dan media-media yang dapat digunakan dalam memasarkan produk olahan mitra. Kegiatan sosialisasi ini bentuk dalam model ceramah dan diskusi.

2. Pelatihan Pembukuan Sederhana untuk usaha, yaitu melatih peserta kegiatan dalam melakukan pencatatan keuangan usaha secara baik, benar dan sesuai dengan kaidah-kaidah pencatatan akuntansi. Peserta dilatih mulai dari mencatat dan mengarsipkan transaksi keuangan, mengenal format-format pencatatan keuangan, membuat jurnal, buku besar, dan laporan keuangan. Model yang dilakukan adalah demontrasi yang dilakukan oleh fasilitator, melatih melalui penyelesaian kasus, dan melakukan pendampingan kepada mitra dalam menyusun laporan keuangannya.

3. Pengenalan Model Pengemasan, yaitu mengenalkan kepada peserta kegiatan cara-cara melakukan pengemasan secara baik serta contoh-contoh pengemasan produk yang menarik. Pada tahap ini, peserta diberi pemahaman tentang pentingnya peningkatan nilai jual serta daya saing melalui pengemasan produk yang diterapkan secara baik. Peserta juga diberi pengetahuan tentang materialmaterial kemasan yang cocok digunakan bagi produk-produk olahan pangan termasuk hasil produksi pangan sagu. 
Beberapa dokumentasi kegiatan sebagai berikut:

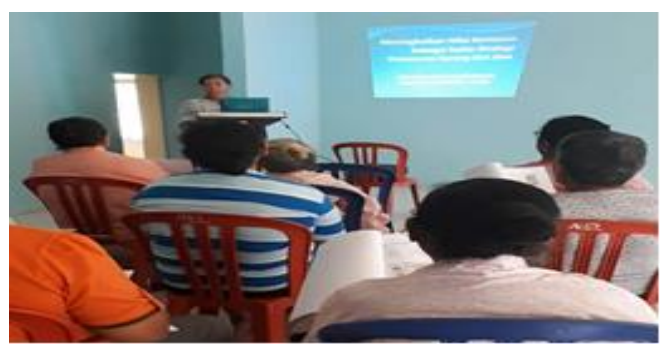

Gambar 2. Pelatihan Kewirausahaan

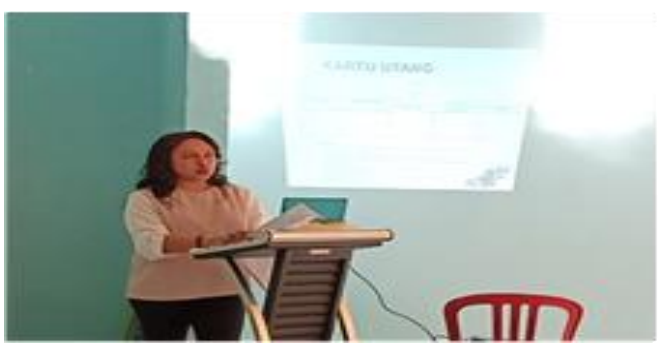

Gambar 3. Pelatihan Pembukuan

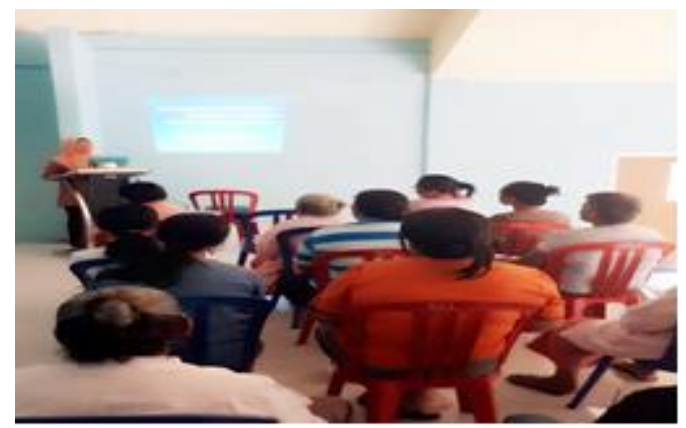

Gambar 4. Pelatihan Model Pengemasan

Berdasarkan Hasil monitoring dan evaluasi serta wawancara langsung dengan peserta kegiatan, maka diketahui bahwa program PKM yang dilaksanakan memiliki dampak sebagai berikut :

\section{Transfer Ilmu Pengetahuan dan Ketrampilan}

a. Sosialisasi Kewirausahaan

Melalui sosialisasi kewirausahaan, mitra sasaran memiliki mental wirausaha yang tinggi dan mampu menghadapi persaingan pasar.

b. Pelatihan Pembukuan Sederhana untuk usaha

Setelah mengikuti Pelatihan ini, mitra mampu menerapkan manajemen usahanya secara baik. Hal ini dapat diukur dari perencanaan usaha yang lebih terarah, dilakukannya pemisahan antara keuangan usaha dan rumah tangga, serta keteraturan dalam pencatatan dan pengelolaan keuangan usaha.

c. Pengenalan model pengemasan

Mitra diperkenalkan dengan model-model pengemasan yang baik terhadap produk olahan pangan. Hal ini berakibat pada semakin menariknya desain kemasan produk dari mitra sasaran. Sebagaimana diketahui bahwa kemasan produk sagu yang dihasilkan mitra sasaran sebelumnya adalah masih dalam bentuk kemasan plasti bening. Setelah mengikuti pengenalan ini, kemasan produk menjadi lebih baik yaitu memiliki label walaupun masih sangat sederhana.

2. Peningkatan Nilai Jual

Melalui program PKM ini, produk olahan sagu yang dihasilkan oleh mitra memiliki peningkatan nilai jual dan daya saing. Produk olahan sagu yang 
dihasilkan tidak lagi hanya dijual secara tradisional disekitah rumah, tetapi telah merambah pasar kota Ambon dan menjadi oleh-oleh khas Maluku.

Dengan memperhatikan hasil yang dicapai dalam kegiatan ini dan mempertimbangkan hasil wawancara maka diketahui bahwa program PKM ini mampu memberikan progres perbaikan terhadap peningkatan daya saing produk olahan kue tradisional berbahan sagu yang dihasilkan oleh mitra sasaran adalah sebesar $70 \%$. Presentasi ini dipandang baik dibanding sebelumnya, dimana mitra memiliki pengetahuan yang rendah terhadap peningkatan daya saing produk.

\section{Simpulan dan Rekomendasi}

Berdasarkan hasil program PKM yang telah dilaksanakan maka dapat disimpulkan bahwa transfer ilmu pengetahuan dan ketrampilan kepada mitra sasaran telah tercapai. Hal ini dapat diukur melalui hasil wawancara dengan mitra sasaran dan memperhatikan hasil penerapan ilmu pengetahuan dan ketrampilan yang diperoleh melalui kegiatan PKM tetsebut.

\section{Acknowledgements}

Kegiatan pengabdian kepada masyarakat ini terselenggara berkat dukungan dana dari Universitas Kristen Indonesia Maluku (UKIM) melalui Lembaga Pengabdian Kepada Masyarakat UKIM.

\section{Daftar Pustaka}

Badan Pusat Statistik Kota Ambon. (2016). Jumlah Penduduk Kota Ambon. https://ambonkota.bps.go.id/statictable/2017/06/07/12/jumlah-pendudukkota-ambon-per-desa-menurut-jenis-kelamin-2016.html

Dismawan. (2014). Kreativitas Produk $\square$ Keaslian $\square$ Tingkat transformasi $\square$ Kelayakan Produk Keunggulan Bersaing $\square$ Bernilai $\square$ Berbeda dengan yang lain $\square$ Tidak mudah digantikan Inovasi Produk. 25. https://elib.unikom.ac.id/files/disk1/650/jbptunikompp-gdl-ranggadism32497-10-unikom_r-f.pdf

Erijanto, A. C., \& Fibrianto, K. (2018). Packaging Variety towards Favorite Levels and Consumers' Decision Making on Purchasing Traditional Foods: Literature Review (Vol. 6, Issue 1).

Hidayat, S. (2010). Daya Saing Ekspor Kopi Robusta Indonesia Di Pasar Internasional. J-Sep, 4(2), 62-82. http:/ / download.portalgaruda.org/article.php?article=95440\&val=5046

Hudayana, B., Kutanegara, P. M., Setiadi, S., Indiyanto, A., Fauzanafi, Z., Nugraheni, M. D. F., Sushartami, W., \& Yusuf, M. (2019). Participatory Rural Appraisal (PRA) untuk Pengembangan Desa Wisata di Pedukuhan Pucung, Desa Wukirsari, Bantul. Bakti Budaya, 2(2), 3. https://doi.org/10.22146/bb.50890 
Husain, F. (2011). 4173-8814-1-Sm. Jurnal Komunitas, 3(1), 40-50.

Imk, P. (2018). tp Pertumbuhan Industri Manufaktur Besar Sedang ( IBS ) dan Industri Mikro Kecil ( IMK) Triwulan IV 2017 go ht tp. 05, 1-8.

Miranda, E. (2013). Pemakaian E-Commerce Untuk Usaha Kecil Dan Menengah Guna Meningkatkan Daya Saing (Vol. 4, Issue 2).

Subagyo Pangestu, M. B. . (2000). Manajemen Operasi (Pertama). BPFE UGM.

Suharman, Nugroho, M., Muq'Asfa, M. W., \& Murti, H. W. (2018). Inovasi, Teknologi dan Peningkatan Daya Saing Industri. Prosiding Seminar Nasional I Hasil Litbangyasa Industri, 137-148. 